\title{
The Effects of Corrective Exercises on Functional Movement Screen Tests of Elite Female Volleyball Players
}

\author{
Elit Kadın Voleybolcularda Düzeltici Egzersizlerin \\ Fonksiyonel Hareket Taraması Test Sonuçlarına Etkileri
}

\author{
Zait Burak Aktuğ ${ }^{1}$, Hasan Aka², Cengiz Akarçeşme³ ${ }^{3}$ Mehmet Mesut Çelebi ${ }^{4}$, Emre Altundağ ${ }^{5}$ \\ ${ }^{1}$ School of Physical Education and Sports, Niğde Ömer Halisdemir University, Niğde, Turkey \\ ${ }^{2}$ Physical Education Teacher, Ministry of Education, Ankara, Turkey \\ ${ }^{3}$ Faculty of Sports Sciences, Gazi University, Ankara \\ ${ }^{4}$ Sports Medicine Department, Faculty of Medicine, Ankara University, Ankara, Turkey \\ ${ }^{5}$ Institute of Health Sciences, Gazi University, Ankara
}

\section{Z. B. Aktuğ \\ 0000-0002-5102-4331 \\ H. Aka \\ 0000-0003-0603-9478 \\ C. Akarçeșme \\ 0000-0001-6231-0950 \\ M. M. Çelebi \\ 0000-0003-0581-6837 \\ E. Altundağ \\ 0000-0001-5258-4982}

Geliş Tarihi/Date Received: 12.12.2018

Kabul Tarihi/Date Accepted: 08.02.2019

Yayın Tarihi/Published Online: 27.03.2019

\section{Yazışma Adresi /}

Corresponding Author:

Zait Burak Aktuğ

Niğde Ömer Halisdemir

Üniversitesi, Beden Eğitimi ve

Spor Yüksekokulu, Niğde,

Turkey

E-mail: zaitburak@gmail.com

(C2019 Türkiye Spor Hekimleri Derneği. Tüm hakları saklıdır.

\section{ABSTRACT}

Objective: 12 weeks of corrective exercises may improve functional movement screen $\left(F M S^{T M}\right.$ ) test scores of elite female volleyball players.

Materials and Methods: Thirteen elite female volleyball players voluntarily participated in the study. The functional movement patterns of the volleyball players were determined through the $\mathrm{FMS}^{\mathrm{TM}}$ test kit. Corrective exercise protocol was applied for 3 times a week during 12 weeks. FMS ${ }^{\mathrm{TM}}$ tests, $\mathrm{FMS}^{\mathrm{TM}}$ total scores and the differences between the pre-test and post-exercise tests were determined by means of the Wilcoxon Signed-Rank Test.

Results: It was determined that total $\mathrm{FMS}^{\mathrm{TM}}$ scores (19.6\%) and shoulder mobility $(87 \%)$ test scores significantly increased following the corrective exercise program. Although an increase in deep squat $(8.3 \%)$, hurdle step $(4.1 \%)$, in line lunge $(18.1 \%)$, push-up $(42.4 \%)$, rotator stability balance $(18.3 \%)$ tests were determined, they were statiscally insignificant.

Conclusion: $\mathrm{FMS}^{\mathrm{TM}}$ total scores which are considered to be an indicator of sports injuries were improved with corrective exercises. Inclusion of corrective exercises in the training schedules may decrease the injury risks.

Key Words: Volleyball, functional movement screen, corrective exercises

ÖZ

Objektif: 12 haftalık düzeltici egzersiz protokolü elit kadın voleybol oyuncularının fonksiyonel hareket taraması (FMS ${ }^{T M}$ ) skorunu olumlu yönde etkileyebilir.

Gereç ve Yöntem: Çalışmaya 13 elit kadın voleybolcu gönüllü olarak katılmıştır. Voleybolcuların fonksiyonel hareket kalıpları $\mathrm{FMS}^{\mathrm{TM}}$ test kiti ile belirlenmiştir. Voleybolculara haftada 3 gün olmak üzere 12 haftalık düzeltici egzersiz protokolü uygulanmıştır. Voleybolcuların $\mathrm{FMS}^{\mathrm{TM}}$ alt testleri ve $\mathrm{FMS}^{\mathrm{TM}}$ toplam skorları ile ön test ve düzeltici egzersizler sonrası son test skorlarının istatistiksel farkları Wilcoxon İşaretli Sıralar Testi ile belirlenmiştir.

Bulgular: Voleybolcuların FMS ${ }^{T M}$ toplam skorları (\%19.6) ve omuz mobilitesi (\%87) test sonuçları son testte istatiksel olarak anlamlı artış göstermiştir $(p<0.05)$. Ayrıca 
FMS $^{\mathrm{TM}}$ alt testlerinden derin çömelme (\%8.3), yüksek adımlama (\%4.1), tek çizgide hamle (\%18.1), gövde stabilite şınavı (\%42.4), rotasyon stabilitesi (\%18.3) sonuçlarında ön test ve son testlerde istatiksel olarak anlamlı bir farklılık olmamasına rağmen, son test skorlarında artış gözlemlenmiştir.

Sonuç: Sonuç olarak, sporcuların yaralanma riskinin belirteci olan $\mathrm{FMS}^{\mathrm{TM}}$ toplam skoru düzeltici egzersizler ile gelişme göstermiştir. Buradan yola çıkarak düzeltici egzersiz programlarının antrenman içeriklerine yerleştirilmesinin sporcuların yaralanma risklerini azaltabileceği düşünülmektedir.

Anahtar sözcükler: Voleybol, fonksiyonel hareket taraması, düzeltici egzersizler

Available at: http://journalofsportsmedicine.org and http://dx.doi.org/10.5152/tjsm.2019.137

Cite this article as: Aktug ZB, Aka $\mathrm{H}$, Akarcesme $\mathrm{C}$, et al. The effects of corrective exercises on functional movement screen tests of elite female volleyball players. Turk J Sports Med. 2019;54(4):233-41.

\section{GíRiş}

Voleybol, basketbol ve futbol gibi sıçrama ve ani dönüşlerin olduğu branşlarda kadın sporcuların erkek sporculara göre yaralanma oranları 4-6 kat daha fazladır (1). Voleybolda sporcular genellikle alt ekstremiteye yönelik yaralanmalar yaşamaktadır (2). Dizde ön çapraz bağ (ACL) yaralanmalarının bește dördü temassız hareketler sonucunda sıçradıktan sonra yere iniş anında gerçekleşmektedir (1). Voleybolda smaç ve blok tekniklerinin çok sayıda sıçrama içermesi yaralanma olasılığını artırmaktadır (3). Ayrıca kas kuvvet dengesizliği, kor bölgesi kuvvet eksikliği veya kas kuvvet kayıları yaralanmalara neden olan diğer faktörlerdir (4).

Spor yaralanmalarının önceden tahmin edilmesi ve önlenmesi sporcularda performansın üst düzeyde sürdürülebilmesi açısından oldukça önemlidir (5). Sporcuların yaralanma olasılıklarını önceden tahmin etmek için kullanılan ölçüm yöntemleri oldukça pahalıdır. Bu ölçüm yöntemlerinde kullanılan bazı ekipmanlar sadece performans analiz laboratuvarlarında bulunmaktadır. Fakat son yıllarda sporcularda yaralanma tahmin aracı olarak kullanılan FMS test bataryası pahalı ekipmanlara ihtiyaç duyulmadan saha içerisinde kolayca uygulanabilen bir ölçüm aracı olmuştur (4). FMS TM testi fonksiyonel hareket kalitesinin belirleyicisi olan 7 temel hareket kalıbı üzerindeki kısıtlılık ve asimetrileri ortaya çıkarmak amacıyla yapılan biyomekaniksel bir tarama ve değerlendirme yöntemidir (4). FMS ${ }^{\mathrm{TM}}$ test bataryası ile kas kuvveti, esneklik, hareket açıklığı, koordinasyon, denge ve propriyosepsiyon gerektiren hareketlerin değerlendirilmesi amaçlanmaktadır (6). Sporcuların fonksiyonel hareket kalıpları kötü ise bu durum sporcunun performansını olumsuz yönde etkiler ve yaralanma riskini arttırabilir (5). Verimli bir fonksiyonel hareket için stabilite ile mobilite gerekmektedir ve bunlar birbirleri ile ilişki içerisindedir (7). FMSTM toplam skoru 14 puanın altında olan sporcuların 14 puandan fazla olanlara göre yaralanma olasılıkları daha yüksek bulunmuştur $(4,5)$. Kiesel ve arkadaşları FMS $^{\mathrm{TM}}$ testi ile iki taraflı yapılan hareketlerde asimetri saptanması durumunda yaralanma riskinin 2 kat fazla olacağını belirtmişlerdir (8). FMS $^{\mathrm{TM}}$ skorlarının riskli seviyelerde olması durumunda farklı antrenman modelleri ile risk düşürülmeye çalışılmaktadır. $\mathrm{Bu}$ yöntemlerin başında düzeltici egzersizler gelmektedir (9).

Farklı branşlardaki sporcularda ve farklı düzeydeki takımlara uygulanan FMS ${ }^{\mathrm{TM}}$ çalışmaları bulunmakla beraber $(10,11)$, elit düzeydeki voleybolculara yönelik düzeltici egzersizlerin FMSTM $^{\mathrm{TM}}$ test sonuçlarına etkisini inceleyen bir çalışmaya rastlanılmamıștır.

$\mathrm{Bu}$ çalışmada voleybolda sıçrama ile smaç ve servis atışlarının genellikle dominant taraf ile yapılmasının asimetriye neden olduğu düşünülerek FMSTM test skorları değerlendirilmiş, düzeltici egzersizlerin bu skorlara etkisi incelenmiştir. Sporculara uygulanacak düzeltici egzersizlerin fonksiyonel hareket kalıplarını etkileyerek iki taraf arasındaki farklılıkları azaltabileceği öngörülmüştür. Böylece voleybolda görülen yaralanma riskinin azaltılabileceği, fonksiyonel hareket becerilerinin geliştirilmesi ile performansın da olumlu etkileneceği beklenmektedir. 


\section{GEREÇ ve YÖNTEM}

$\mathrm{Bu}$ çalışma Gazi Üniversitesi etik kurulunun 10/12/2018 tarih ve 2018/911 sayılı raporu ile onaylanmıştır. Araştırmaya voleybolda en üst kategori olan Vestel Venüs Sultanlar Liginde mücadele eden Halkbank Spor Kulübü Kadın Voleybol takımından 13 elit voleybolcu gönüllü olarak katılmıştır. Voleybolcuların spor yaşı ortalaması $11.38 \pm 4.07$ 'dir. Çalışmada yer alan voleybolcular son 6 ay içerisinde herhangi bir spor yaralanması geçirmemişlerdir. Testler yarıșma döneminde voleybolcuların 2 gün izin yaptıkları ve son 24 saat içerisinde herhangi bir sportif aktiviteye katılmadıkları zamanda uygulanmıştır. Ölçümler saat $12.00-16.00$ saatleri arasında yapılmıştır. Her sporcu için testler yaklaşık 20 dakika sürmüş ve bütün sporcuların ölçümleri aynı gün içinde tamamlanmıştır.

\section{Veri Toplama Araçları}

\section{Boy Uzunluğu ve Vücut Ağırlığı Ölçümleri}

Voleybolcuların boy ve vücut ağırlığı boy ölçerli baskül (Seca 700; Seca GmbH \& Co. KG., Hamburg, Germany) kullanılarak çıplak ayak ve üzerlerinde şort ve tişört varken ölçülmüştür.

\section{Fonksiyonel Hareket Tarama (FMS ${ }^{\mathrm{TM}}$ ) Testi}

Voleybolculara uygulanan FMSTM testi Gray Cook tarafından geliştirilen Fonksiyonel Hareket Tarama Test kiti kullanılarak belirlenmiştir (12). Ölçümler sertifikalı bir uzman tarafından yapılmıştır. Uygulanan testteki hareketler sırasıyla, derin çömelme (Şekil 1), yüksek adımlama (Şekil 2), tek çizgide hamle (Şekil 3), omuz mobilitesi (Şekil 4), aktif düz bacak kaldırma (Şekil 5), gövde stabilite şınavı (Şekil 6), rotasyon stabilitesidir (Şekil 7). Ölçümler ısınma yaptırılmadan gerçekleştirilmiştir. Voleybolculara ölçümler başlamadan önce test hakkında bilgi verilmiş ve sonrasında uygulamalı olarak gösterilmiştir. Her bir ölçüm üçer kez tekrarlanmıştır. Voleybolculardan uygulama sırasında oluşabilecek bir ağrı veya rahatsızlık durumunu ölçüm yapan uzmana bildirmeleri istenmiştir. Testte önce kendi içinde tek taraflı değerlendirilen hareketler (derin çömelme, gövde rotasyon şınavı) ölçülmüştür. İki taraflı ölçülen testlerde ise (yüksek adımlama, tek çiz- gide hamle, omuz mobilitesi, aktif düz bacak kaldırma ve rotasyon stabilitesi) sağ ve sol olmak üzere ayrı ayrı puanlama yapılmıştır. Puanlama sırasında katılımcıların vücutlarının her iki tarafından alınan skorlar kaydedilmiştir. Fakat hareketten aldığı en düşük puan testin sonucu olarak kabul edilmiştir. Her bir değerlendirmeye 0 ile 3 arasında puan verilmektedir. En yüksek

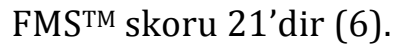

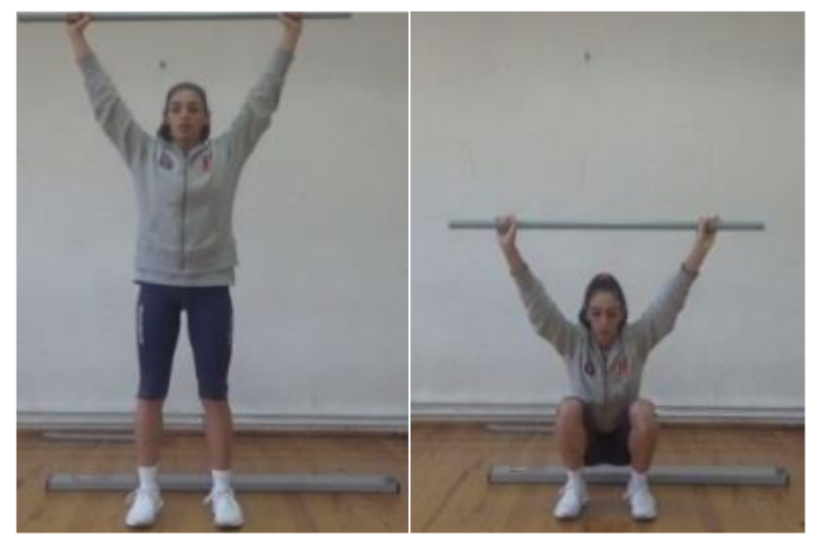

Şekil 1. Derin çömelme

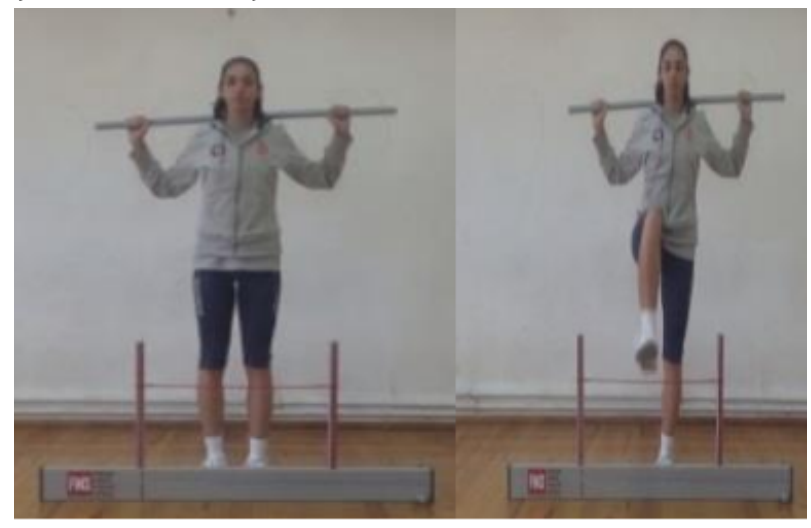

Şekil 2. Yüksek adımlama

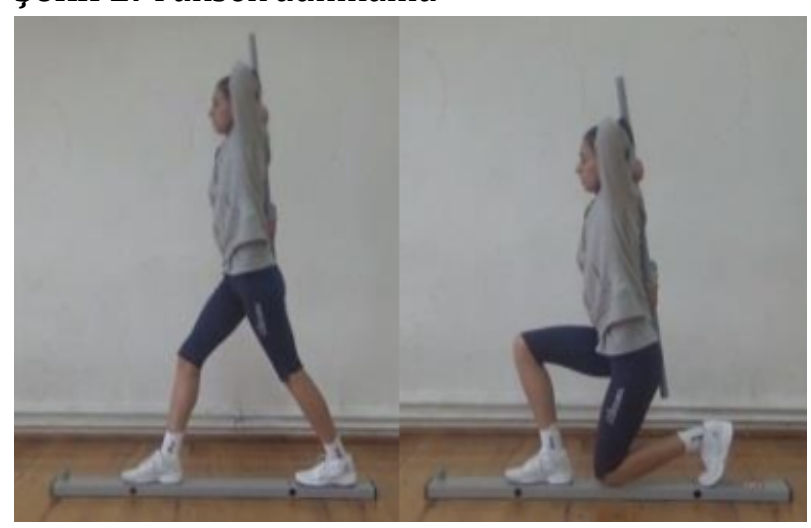

Şekil 3. Tek çizgide hamle 


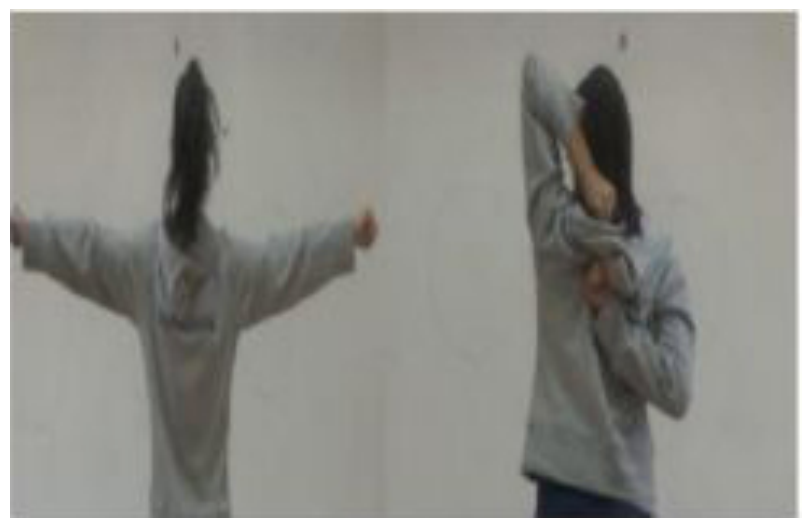

Şekil 4. Omuz mobilitesi

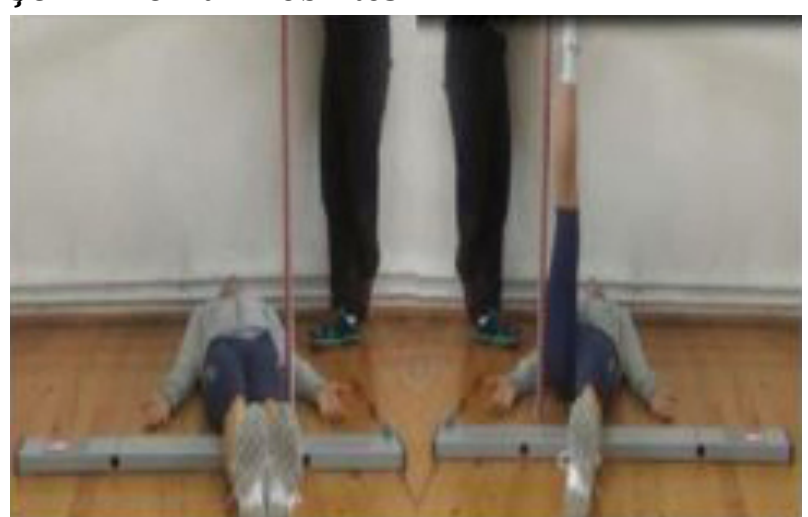

Şekil 5. Aktif düz bacak kaldırma

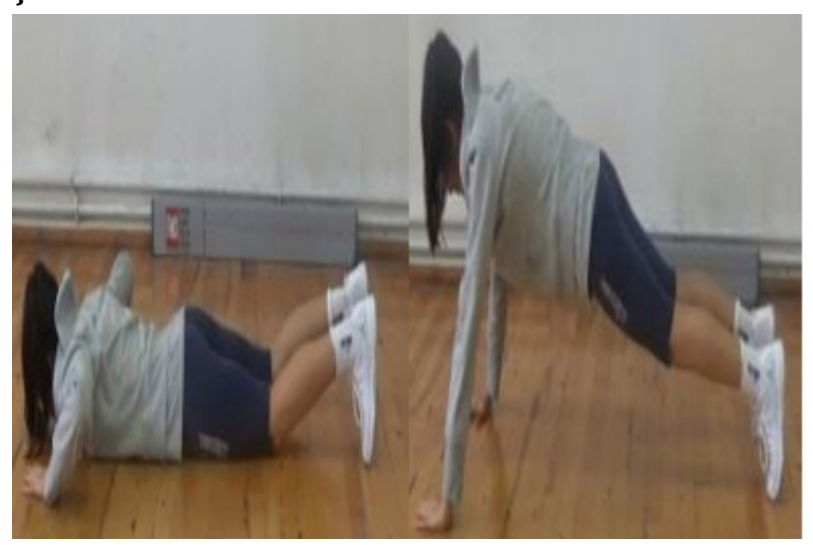

Şekil 6. Gövde stabilite şınavı

\section{Düzeltici Egzersizler (Corrective Exercises)}

$\mathrm{Bu}$ egzersizler 12 hafta boyunca haftada 3 gün antrenman öncesinde uygulanmış ve ana antrenmanı aksatmayacak şekilde planlanmıştır. Çalışmamızda onlarca FMS düzeltici egzersizi arasından seçilen ve FMS skorlarını geliştireceği düşünülen hareketlerden oluşan bir protokol uygulanmıştır. Protokolde yer alan öne basışı geliştirme (toe touch progression), ayak bileği

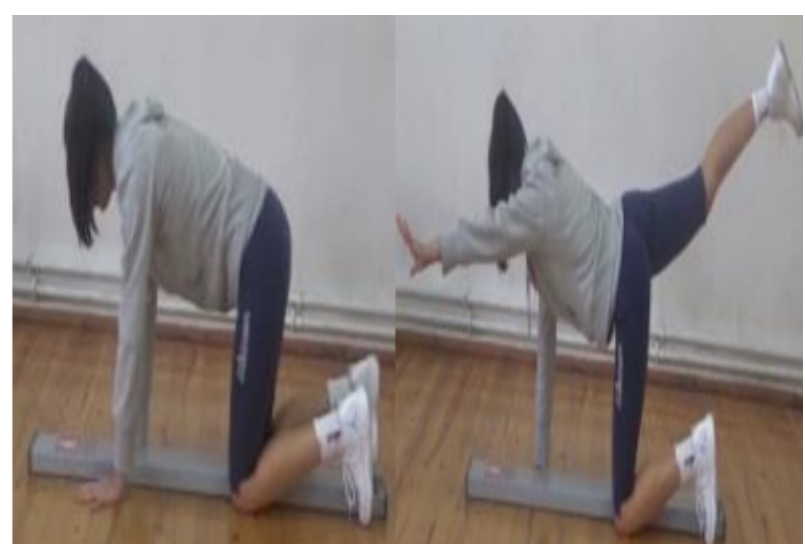

Şekil 7. Rotasyon stabilitesi

mobilitesi (ankle mobility), tek bacak kalça menteşe (single leg hip hinge), torasik mobilite (thoracic mobilty), kuvvet bandı ile derin çömelme (power band deep squat)) egzersizleri 10 tekrar ve 2 set olarak planlanmıştır. Düzeltici egzersizler voleybola özgü temel hareket kalıplarını geliştirebileceği düşünülen hareketler arasından seçilmiştir. Düzeltici egzersiz olarak uygulanan öne basışı geliştirme egzersizi tek çizgide hamle testi ile, tek bacak kalça menteşe egzersizi aktif düz bacak kaldırma testi ile, torasik mobilite egzersizi rotasyon stabilitesi ve gövde stabilite şınavı testleri ile, ayak bileği mobilite egzersizi yüksek adımlama testi ile, kuvvet bandı ile derin çömelme egzersizi derin çömelme ve tek çizgide hamle testleri ile ilişkilendirilmiştir.

\section{Öne basışı geliştirme (Toe Touch Progres- sion) egzersizi}

Gözler karşıya bakacak şekilde baş dik konumda, eller "foam roller" üzerine konulmuş olarak harekete başlanır. Kollar baş üstünde gergin, dizler egzersiz esnasında dışa açık olur. Hareket sırasında parmak uçları paralel olacak şekilde karşıyı göstermelidir. Bu konum alındıktan sonra sırasıyla önce sağ el, sonra sol el yukarı kaldırılmalıdır. Şekil 8'de hareketin başlangıç ve bitiriş aşamaları gösterilmiştir. Bu hareket 10 tekrar 2 set olarak uygulanmıştır. 


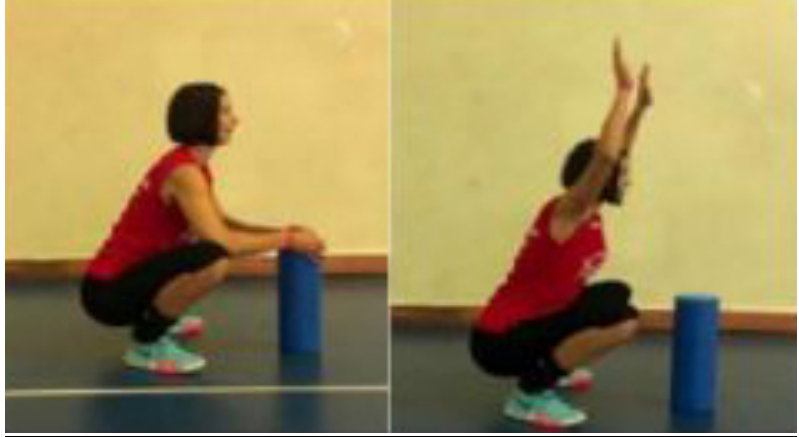

Şekil 8. Öne basışı geliştirme egzersizi

\section{Ayak bileği mobilitesi (Ankle Mobility) eg- zersizi}

Öncelikle kuvvet çalışma bandı ayak bileğine takılır ve bir yere sabitlenir, diz $90^{\circ}$ fleksiyon pozisyonuna getirilir. Parmak ucu karşıyı göstermeli, kalça hizasında dik durulmalı ve karşıya bakılmalıdır. $\mathrm{Bu}$ pozisyon alındıktan sonra diz parmak ucunu geçene kadar öne eğilmeli ve topuk yerden kalkmamalıdır. Şekil 9'da hareketin başlangıç ve bitiriş aşamaları gösterilmiştir. $\mathrm{Bu}$ hareket 10 tekrar 2 set olarak uygulanmıștır.

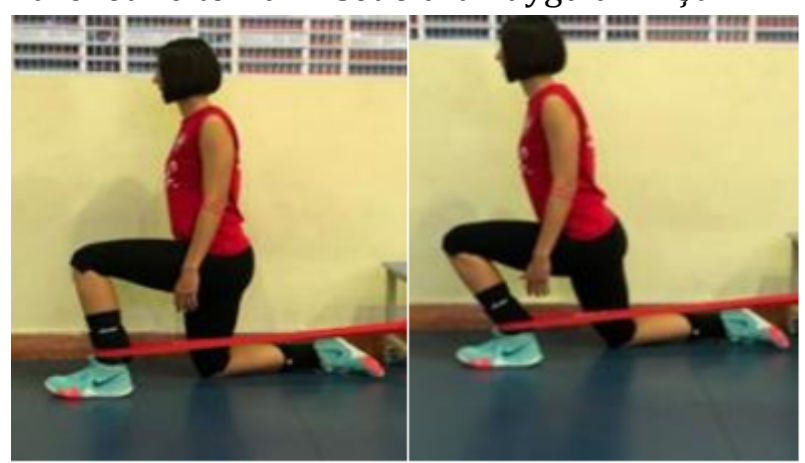

Şekil 9. Ayak bileği mobilitesi egzersizi

\section{Tek bacak kalça menteşe (Single Leg Hip Hinge) egzersizi}

Uzun bir tahta gövdenin tam ortasına yerleștirilip, baş, sırt ve kalça üzerinde düz konumda durması sağlanmalıdır. Kişi tek ayak üzerinde dizini $10-15^{\circ}$ bükerek dengede kalır ve kalça ekleminden öne doğru eğilir. Egzersiz sırasında dizin içe doğru gitmemesine dikkat edilmelidir. Diğer bacak dışa dönmeden stabil konumda kalınmalıdır. Omurga egzersiz boyunca düz pozisyonda olmalıdır. Şekil 10'da hareketin başlangıç ve bitiriş aşamaları gösterilmiştir. Bu hareket 10 tekrar 2 set olarak uygulanmıştır.

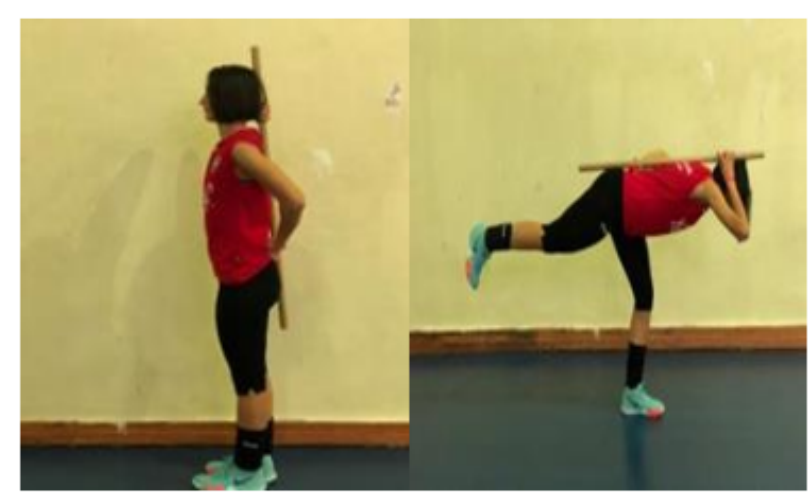

Şekil 10. Tek bacak kalça menteşe egzersizi

\section{Torasik mobilite (Thoracic mobility) egzer-} sizi

Egzersize emekleme pozisyonunda başlanır. Dizler $90^{\circ}$ fleksiyonda, omuz düz pozisyondadır. Hareketin yapılacağı taraftaki elin avuç içi enseye yerleştirilir. Gövdeye diagonal (çapraz) düzlemde rotasyon yaptırılır. Egzersiz büyük açılarda yapılmalı ve ağrı hissedilmemelidir. Kalça ve bel bölgesi sabit kalmalıdır. Şekil 11'de hareketin başlangıç ve bitiriş aşamaları gösterilmiştir. Bu hareket 10 tekrar 2 set olarak uygulanmıştır.

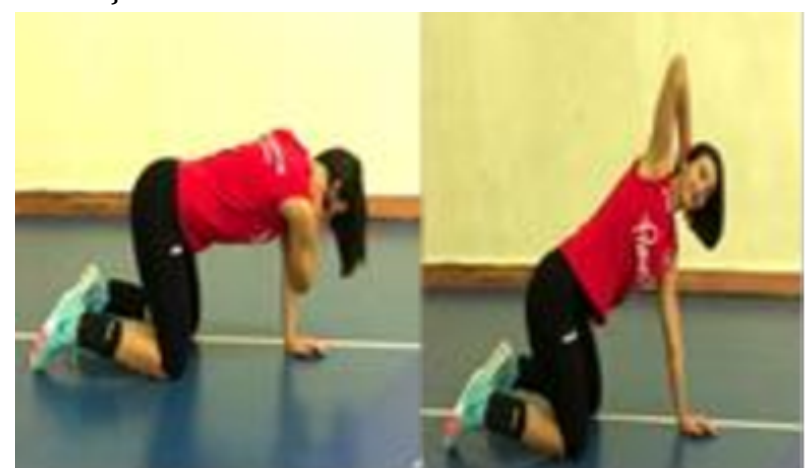

Şekil 11. Torasik mobilite egzersizi

\section{Kuvvet bandı ile derin çömelme (Power Band Deep Squat) egzersizi}

Kuvvet bandı dizlerin arkasına gelecek şekilde konumlandırılır. Ayaklar karşıyı gösterir șekilde paralel pozisyonda kalır. Eş yardımı ile kuvvet bandı mümkünse çapraz bir şekilde tutulur (dizleri içeri çekecek şekilde), kollar baş üstünde olacak şekilde gergin bir pozisyon alınır. Tam derin çömelme pozisyonuna inilir ve gövde dik gözler karşıya bakacak şekilde konumlandırılır. Dizin valgusa (içe) gitmemesi önemlidir. Egzersizin yapılış şekli kontrollü ve yavaş olmalıdır. 
Özellikle en aşağıda birkaç saniye beklenmelidir. Şekil 12'de hareketin başlangıç ve bitiriş aşamaları gösterilmiştir. Bu hareket 10 tekrar 2 set olarak uygulanmıştır.

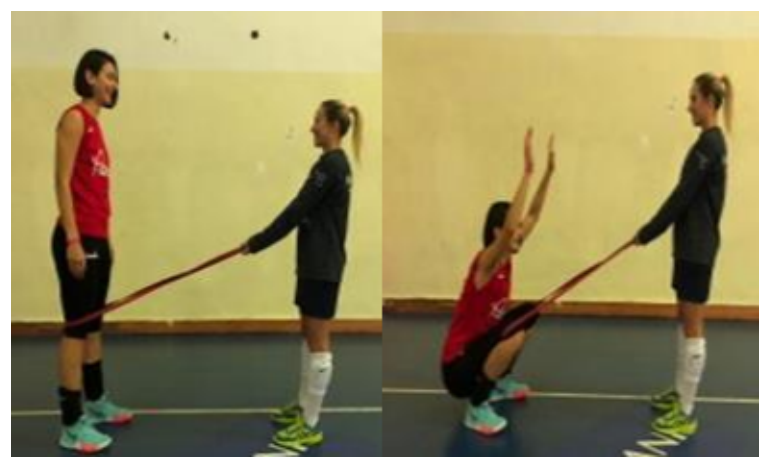

Şekil 12. Kuvvet bandı ile derin çömelme egzersizi

\section{Verilerin Analizi}

Elde edilen veriler SPSS 24.0 programında analiz edilmiştir. Voleybolcuların FMSTM alt testlerinin ve FMSTM toplam skorlarının ilk test ve son testleri arasındaki farkı belirlemek için nonpa- rametrik testlerden Wilcoxon İşaretli Siralar Testi kullanılmıştır. Çalışmada anlamlılık düzeyi $\mathrm{p}<0.05$ olarak kabul edilmiştir.

\section{BULGULAR}

Tablo 1. Voleybolcuların tanımlayıcı istatistikleri

\begin{tabular}{|l|l|l|l|l|l|}
\hline Değişken & $\mathbf{N}$ & Ortalama & SS & Min. & Mak. \\
\hline Yaş (yıl) & 13 & 24,15 & 4,76 & 17 & 33 \\
\hline Boy (m) & 13 & 1,81 & 0,07 & 1,68 & 1,92 \\
\hline $\begin{array}{l}\text { Vücut } \\
\text { Ağırlığı }\end{array}$ & 13 & 71,54 & 11,35 & 51 & 87 \\
\hline $\begin{array}{l}\text { VKi் } \\
\text { (kg/m }\end{array}$ & 13 & 21,66 & 2,51 & 17,65 & 25,95 \\
\hline
\end{tabular}

Min= Minimum, Mak=Maksimum, SS=Standart sapma $\mathrm{N}=$ Katılımcı sayısı

Tablo 2 incelendiğinde voleybolcuların omuz mobilitesi ve FMSTM toplam skorlarının egzersiz programı sonrasında istatistiksel olarak anlamlı şekilde arttı̆̆

Tablo 2. Başlangıç ve düzeltici egzersiz programı sonrası FMSTM ölçümlerine ait sonuçlar

\begin{tabular}{|c|c|c|c|c|c|}
\hline Değişken & Eşli Grup & $\mathbf{N}$ & Ortalama & SS & $\mathbf{p}$ \\
\hline \multirow{2}{*}{ Derin çömelme } & Ön Test & 13 & 1,92 & 0,28 & \multirow{2}{*}{0,32} \\
\hline & Son Test & 13 & 2,08 & 0,49 & \\
\hline \multirow{2}{*}{ Yüksek adımlama } & Ön Test & 13 & 1,92 & 0,49 & \multirow{2}{*}{0,56} \\
\hline & Son Test & 13 & 2,00 & 0,41 & \\
\hline \multirow{2}{*}{ Tek çizgide hamle } & Ön Test & 13 & 2,15 & 0,38 & \multirow{2}{*}{0,06} \\
\hline & Son Test & 13 & 2,54 & 0,66 & \\
\hline \multirow{2}{*}{ Omuz mobilitesi } & Ön Test & 13 & 1,15 & 1,14 & \multirow{2}{*}{$0,05^{*}$} \\
\hline & Son Test & 13 & 2,15 & 0,80 & \\
\hline \multirow{2}{*}{ Aktif düz bacak kaldırma } & Ön Test & 13 & 2,62 & 0,51 & \multirow{2}{*}{1,00} \\
\hline & Son Test & 13 & 2,62 & 0,51 & \\
\hline \multirow{2}{*}{ Gövde stabilite şınavı } & Ön Test & 13 & 1,46 & 1,45 & \multirow{2}{*}{0,25} \\
\hline & Son Test & 13 & 2,08 & 1,04 & \\
\hline \multirow{2}{*}{ Rotasyon stabilitesi } & Ön Test & 13 & 1,69 & 0,75 & \multirow{2}{*}{0,16} \\
\hline & Son Test & 13 & 2,00 & 0,00 & \\
\hline \multirow{2}{*}{ FMSTM toplam skor } & Ön Test & 13 & 12,92 & 2,63 & \multirow{2}{*}{$0,03^{*}$} \\
\hline & Son Test & 13 & 15,46 & 2,30 & \\
\hline
\end{tabular}

SS=Standart sapma N=Katılımcı sayıSl, FMS ${ }^{T M}$ : Fonksiyonel hareket taraması 


\section{TARTISMA}

FMSTM toplam skorunun kritik sınırı 14 puan olarak belirlenmiştir. 14 puanın altında alan sporcuların yaralanma riskleri yüksek olarak kabul edilirken, FMS ${ }^{\mathrm{TM}}$ toplam skorları arttıkça yaralanma oranlarının azaldığı belirtilmektedir $(5,13)$. Bu çalışmada 12 haftalık düzeltici egzersizlerin voleybolcuların omuz mobilitesi ve FMS $^{\mathrm{TM}}$ toplam skorlarında anlamlı gelişme sağladığı saptanmıştır. Voleybolcuların FMSTM ilk ölçüm toplam skorları 12,92 olarak belirlenirken, 12 haftalık düzeltici egzersizler sonucunda FMSTM toplam skorları 15,46 puana yükselmiştir.

Benzer bir çalışmada Kiesel ve ark. profesyonel futbolculara uyguladıkları düzeltici egzersizler

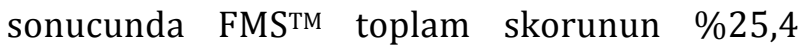
oranında arttığını belirlemişlerdir (14). Ayrıca düzeltici egzersizlerin sporcuların hareket kalitesini artırdığı ve yaralanma riskini azalttığını belirtmişlerdir. Farklı egzersizlerin FMSTM toplam test skorlarını geliştirdiğini gösteren çalışmalar da bulunmaktadır. $\mathrm{Bu}$ araştırmalardan birisinde Linek ve ark. genç voleybolculara yönelik 8 haftalık stabilizasyon antrenmanları sonucunda derin çömelme (\%27), gövde stabilite şınavı (\%21), rotasyon stabilitesi (\%67) ve FMSTM toplam skorlarinda (\%75) önemli artışlar bulmuşlardır (15). Başka bir çalışmada Goss ve ark. 6 hafta uygulanan tek bacak sıçrama, tekme atma ve dikey sıçrama egzersizleri sonucunda FMSTM test skorunda \%16'lık artış saptamışlardır (16). Bu sonuç bizim çalışmamızla benzerlik göstermektedir. Bir başka çalışmada erkek çocuklara uygulanan düzeltici egzersizlerin kamburluk ve bel çukurluğu oranlarında azalma sağladığı vurgulanmıștır (17).

Kullanılan egzersiz programının stabilizasyona yönelik olduğu düşünüldüğünde bu çalışmaların sonuçlarının çalışmamızla benzer olduğu görülmektedir.

Voleybolda sporcuların dominant omuzlarının diğer tarafa oranla daha çok kullanıldığı için daha kuvvetli olabileceği ve iki taraf arasındaki farkın fazla olacağı varsayılmaktadır. Ayrıca bir omuzda eksternal rotasyon olurken, karşı omuzda internal rotasyon ve adduksiyon hareketi olması gerekmektedir (12). Bu çalışmada omuz mobilitesi testinden elde edilen puanların egzersiz programı sonunda istatiksel olarak anlamlı biçimde arttığı görülmektedir. Üst ekstremitenin daha aktif kullanıldığı bir branş olan voleybolda, sporcuların omuz kuşağı kasları, omuz eklemi ve torasik omurga hareketliliğinde görülen farklılıkların düzeltici egzersizlerle azaldığı belirlenmiștir.

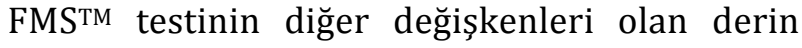
çömelme, yüksek adımlama, tek çizgide hamle, gövde stabite şınavı, rotasyon stabilitesi üzerine 12 haftalık düzeltici egzersizlerin test skorlarında gelişme sağladığı belirlenmesine karşın istatistiksel olarak anlamlı bir fark tespit edilememiştir. Yapılan çalışmalar incelendiğinde düzenli olarak yapılan düzeltici egzersizlerin sirt ekstansör kasları (18) ile genel vücut kaslarının kuvvetini (19) arttırdığı görülmektedir. Bir çalışmada sporculara uygulanan FMSTM antrenman programı sonunda sporcuların kuvvet ve esnekliğinin önemli ölçüde arttığı belirlenmiştir (20). Ghorbani ve ark. düzeltici egzersizlerin hastaların sırt ağrılarını azalttığını ve mental iyilik sağladığını göstermişlerdir (21). Başka bir çalışmada 8 hafta uygulanan düzeltici egzersizlerin hamstring kasının esnekliğine ve kuvvetine pozitif bir etki sağladığı tespit edilmiștir (22).

Bu çalışmada düzeltici egzersiz programları haftada 3 gün ve 2 set olarak uygulanmıştır. Yarışma döneminde uygulanan program voleybolcuların derin çömelme, yüksek adımlama, tek çizgide hamle, gövde stabilite şınavı, rotasyon stabilitesine olumlu katkı sağlamasına rağmen istatiksel olarak anlamlı bir fark yaratamamıştır. Düzeltici egzersizlerin set sayıları, set içerisindeki tekrar sayısı, haftalık uygulama sıklığı veya uygulanan toplam süre artırllırsa FMSTM $^{\mathrm{TM}}$ test skorlarını anlamlı ölçüde etkileyebilir. Fonksiyonel eksiklikler ve spor branşları dikkate alınarak hazırlanan programlar sayesinde sporcular branşlarının gerekliliklerini yerine getirebilecek fonksiyonel yeterliliğe ulaşabilirler ve performansları artabilir (23). 
$\mathrm{Bu}$ çalışmada elde edilen FMSTM toplam skorlarının kritik sınır olarak kabul edilen 14 puandan yüksek olması yaralanma olasılığının düşük olduğunu göstermektedir. Ayrıca uygulanan düzeltici egzersizler sonucunda FMS $^{\mathrm{TM}}$ toplam puanındaki artış sporcuların fonksiyonel durumlarının daha da geliştirilebilir olduğunu düşündürmektedir. Düzeltici egzersizlerin sporcuların motor kontrolünü, stabilite ve mobilite özelliklerini geliştirebileceği ve iki taraflı hareketlerde zayıf olan tarafın kuvvet gelişimini sağlayarak yaralanmaları önleyebileceği düşünülmektedir. Sporcuların özellikle sezon öncesi hazırlık döneminde fonksiyonel hareket kalıplarını geliştirebilmeleri için bilinçlendirilmesi ve bu doğrultuda çalışmalara yönlendirilmesi önerilebilir. Ayrıca antrenörlerin, atletik performans uzmanlarının ve beden eğitimi öğretmenlerinin hazırlamış oldukları antrenman programlarında fonksiyonel hareketlerin geliştirilmesine yönelik egzersizlere yer vermelerinin gerekli olduğu düşünülmektedir.

$\mathrm{Bu}$ çalışmaya katılan sporcu sayısının az olması, sadece voleybol branşının ve kadın sporcuların dahil edilmesi çalışmanın ana sınırlılıkları olarak düşünülebilir. Farklı spor branşlarında ve farklı yaş gruplarında benzer çalışmaların yapılmasına ihtiyaç vardır.

\section{KAYNAKLAR}

1. Hewett TE, Stroupe AL, Nance TA, et al. Plyometric training in female athletes. Decreased impact forces and increased hamstring torques. Am J Sports Med. 1996; 24(6): 765-73.

2. Marwan Y, Behbehani A, Al-Mousawi A, et al. Sports injuries among professional male athletes in Kuwait: prevalence and associated factors. Med Princ Pract. 2012; 21(1): 171-7.

3. Solgard L, Buhl Nielsen A, Mdler-Madsen B, et al. Volleyball injuries presenting in casualty. A prospective study. Br J Sports Med. 1995; 29(3): 2004.

4. Chorba RS, Chorba DJ, Bouillon LE, et al. Use of a functional movement screening tool to determine injury risk in female collegiate athletes. $N \mathrm{Am} J$ Sports Phys Ther (NAJSPT). 2010; 5(2): 47-54.

5. Kiesel K, Plisky PJ, Voight ML. Can serious injury in professional football be predicted by a preseason functional movement screen? $N$ Am J Sports Phys Ther (NAJSPT). 2007; 2(3): 147-58.
6. Cook G, Burton L, Kiesel K, Rose G, Braynt MF, editors. Movement: Functional Movement Systems: Screening, Assessment, and Corrective Strategies. 1st ed. Aptos: On Target Publications; 2010.

7. Hamilton $\mathrm{N}$, Weimar $\mathrm{W}$, Luttgens $\mathrm{K}$, editors. Kinesiology. Scientific Basis of Human Motion. 12th ed. New York: McGrew-Hill Comparies Inc; 2002.

8. Kiesel K, Plisky P, Kersey P. Functional movement test score as a predictor of time- loss during a professional football team's pre-season. American College of Sports Medicine Annual Conference; 2008 May 28-31; Indianapolis, Indiana.

9. Mokha M, Sprague PA, Gatens DR. Predicting musculoskeletal injury in national collegiate athletic association division II athletes from asymmetries and individual-test versus composite functional movement screen scores. J Athl Train. 2016; 51(4): 276-82.

10. Bardenett SM, Micca JJ, DeNoyelles JT, et al. Functional movement screen normative values and validity in high school athletes: can the FHTTM be used as a predictor of injury? Int J Sports Phys Ther. 2015; 10(3): 303-8.

11. Li Y, Wang X, Chen X, et al. Exploratory factor analysis of the functional movement screen in elite athletes. $J$ Sports Sci. 2015; 33(11): 1166-72.

12. Cook G, Burton L, Hoogenboom B. Pre-participation screening: the use of fundamental movements as an assessment of function-part 1. N Am J Sports Phys Ther (NAJSPT). 2006; 1(2): 62-72.

13. Güzel NA, Kafa N, editors. Sporcu Sağlığı. 1st ed. Ankara: Sözkesen Matbaacılık; 2017.

14. Kiesel K, Plisky P, Butler R. Functional movement test scores improve following a standardized off-season intervention program in professional football players. Scand J Med Sci Sports. 2011; 21: 287-92.

15. Linek P, Saulicz E, Mysliwiec A, et al. The effect of specific sling exercises on the fonctional movement screen in adolescent volleyball players: A preliminary study. J Hum Kinet. 2016; 15(54): 83-90.

16. Goss DL, Christopher GE, Faulk RT, et al. Functional training program bridges rehabilitation and return to duty. J Spec Oper Med. 2009; 9(2): 29-48.

17. Yazıcı AG, Mohammadi M. The effect of corrective exercises on the thoracic kyphosis and lumbar lordosis of boy students. Turk J Sport Exe. 2017; 19(2): 177-81.

18. MajidiSiahtan S, Behbudi L. The impact of 8-week selected pilates exercises on lordosis correction and BMI in female teens aged 15-18. Biological Forum International Journal. 2015; 7(1): 1267-71.

19. Choi EH, Hur JK, Yang JI, et al. The effect of thoracic exercise program on thoracic pain, kyphosis, and spinal mobility. Arch Phys Med Rehabil. 2005; 86(9): 23.

20. Song HS, Woo SS, So WY, et al. Effects of 16-week functional movement screen training program on 
strength and flexibility of elite high school baseball players. J Exerc Rehab. 2014; 10(2): 124-30.

21. Ghorbani L, Ghasemi G. Effects of eight weeks corrective exercises on lumbar lordosis. J Res Rehabil Sci. 2008; 3(2): 59-71.

22. Abbaszadeh A, Sahebzamani M, Seifadini MA, et al. Effect of an 8-week corrective exercise on hyperlordosis girl students. Hormozgan Medical Journal. 2012; 16(5): 377-86.

23. Cowen VS. Functional fitness improvements after a worksite-based yoga initiative. J Bodyw Mov Ther. 2010; 14(1): 50-4. 